\title{
Application of accelerated rehabilitation surgery concept in laparoscopic radical gastrectomy cancer for patients aged $\geq 70$ years
}

Jun Ma

Zhejiang Provincial People's Hospital

Hongliang Shao

The fifth people hospital of fuyang

Yanzhong Wang

Zhejiang University School of Medicine Sir Run Run Shaw Hospital

Yirui Chen

Zhejiang Provincial People's Hospital

Yiping Mou ( $\nabla$ yp66self@163.com )

Zhejiang Provincial People's Hospital

Technical advance

Keywords: Enhanced recovery after surgery, Laparoscopic, Gastric cancer, Elderly patients.

Posted Date: September 21st, 2020

DOI: https://doi.org/10.21203/rs.3.rs-56684/v2

License: (c) (1) This work is licensed under a Creative Commons Attribution 4.0 International License.

Read Full License 


\section{Abstract}

Background: To explore the application effect of accelerated rehabilitation surgery on laparoscopic radical gastrectomy cancer for patients aged $\geq 70$ years.

Methods: Retrospective analysis of 120 aged $\geq 70$ patients' clinical data undergoing laparoscopic radical gastrectomy in our hospital from January 2017 to December 2018, which were divided into accelerated rehabilitation group $(n=73)$ and control group $(n=47)$. By comparing the postoperative clinical data of the two groups, we explored the application effect of accelerated rehabilitation surgery on laparoscopic radical gastrectomy cancer for patients aged $\geq 70$ years.

Results: Compared with the control group, the first time to get out of bed ( $2.1 \pm 0.9$ days vs $3.8 \pm 1.5$ days, $P<0.01)$, the first exhaust time ( $3.2 \pm 0.8$ days vs $3.9 \pm 1.2$ days, $P<0.01)$ and the first time to eat liquid food after surgery $(1.8 \pm 0.9$ days vs $3.2 \pm 1.3$ days, $P<0.01)$, and postoperative hospital stay $(12.7 \pm 4.3$ days vs $15.8 \pm 6.4$ days, $P<0.01)$ in the rehabilitation group were significantly lower. There was no significant difference in the overall postoperative complications between the two groups $(P<0.05)$, however, the complications of pulmonary infection in the accelerated rehabilitation group was significantly lower than that in the control group $(1.4 \%$ vs $10.6 \%, \mathrm{P}=0.03)$.

Conclusions: The application of accelerated rehabilitation surgery concepts and measures after surgery in laparoscopic radical gastrectomy cancer for patients aged $\geq 70$ years can promote early postoperative rehabilitation, reduce postoperative hospital stay, and reduce the incidence of postoperative pulmonary infection complications.

\section{Background}

Enhanced recovery after surgery (ERAS) refers to multi-modal management during perioperative period, reducing the patient's surgical stress response and complications, and facilitating recovery, which is currently relatively mature in colorectal surgery $[1,2]$. In recent years, ERAS is claimed to be safe and feasible in gastric cancer surgery, and well promoted in the research [3-5]. However, there is few reports about the ERAS in laparoscopic gastric cancer surgery for elderly patients. With the rapid development of surgical technology and the promotion of the concept and measures of ERAS, it is significant to analyze the influences of ERAS in the perioperative period of laparoscopic gastric cancer surgery for elderly patients. This study aims to investigate the effect of accelerated rehabilitation surgery on laparoscopic radical gastrectomy cancer in patients aged $\geq 70$ years.

\section{Methods}

\section{General information}

In the study, we collected the clinical data of 120 patients aged $\geq 70$ years with laparoscopic radical gastrectomy in Department of Gastrointestinal and Pancreatic Surgery, Zhejiang People's Hospital from 
January 2017 to December 2008. Patients were divided into two groups, ERAS group and control group. The clinical data included age, gender, body mass index (BMI), preoperative comorbidity, American Society of Anesthesiologists (ASA) classification, surgical procedure, reconstruction mode, operative time, intraoperative blood loss, number of lymph nodes, and cancer staging.

\section{Inclusion and Exclusion}

Inclusion criteria: 1) age of patients $\geq 70$ years, 2) patients could adopt laparoscopic radical gastrectomy by preoperative assessment, 3 ) patients were confirmed as gastrectomy cancer by postoperative pathology, 4) patient informed consent, 5) patient undergo laparoscopic radical gastrectomy, 6) clinical data intact, 7) patient had no distant metastasis.

Exclusion criteria: 1) patients with severe cardiopulmonary disease could not tolerate laparoscopic surgery; 2) patients were transferred to open surgery, 3) tumor invaded adjacent organs and was accepted expand resection, 4) patient had distant organ metastasis.

\section{Observation indicators and discharge criteria}

The time of first post-operative activity, eat liquid food after surgery, anal recovery exhaust time, postoperative complications and postoperative hospital stay were observed. The discharge criteria of the two groups are the same: eating semi-liquid without discomfort and without intravenous rehydration, defecation is normal, pain is under control, movement is free, and abdominal drainage tube has been pulled out.

\section{Statistical methods}

Data analysis was performed using SPSS.20 statistical software. Continuous variables were expressed as mean $\pm S D$, and $t$-tests were used for comparison between two groups. The categorical variable is expressed as a percentage, using the chi-square test. The significant difference is expressed by $\mathrm{P}<0.05$.

\section{Results}

\section{The comparison of general data before surgery and management measures during surgery}

The general data of the two groups of patients was extracted, including age, BMI, American Society of Anesthesiologists (ASA) score, comorbidity, tumor stage, surgical method, reconstruction method, operation time, amount of bleeding and number of lymph node dissections. There was no significant difference of these data between the two groups (Table 1).

Table 1: Comparison of general data between the two groups of patients 


\begin{tabular}{|c|c|c|c|}
\hline Group & Accelerated rehabilitation group $\square \mathrm{n}=73 \square$ & $\begin{array}{c}\text { Control group } \\
(\mathrm{n}=47)\end{array}$ & $\mathrm{P}$ value \\
\hline Age (year) & $73.5 \pm 3.5$ & $73.6 \pm 3.6$ & 0.09 \\
\hline Gender (male/female) & $52 / 21$ & $35 / 12$ & 0.90 \\
\hline BMI $\left(\mathrm{Kg} / \mathrm{m}^{2}\right)$ & & & 1.0 \\
\hline$<18$ & 3 & 2 & \\
\hline $18-24$ & 56 & 35 & \\
\hline $24-29$ & 10 & 7 & \\
\hline$\geq 29$ & 4 & 3 & \\
\hline ASA score & & & 0.35 \\
\hline I & 20 & 15 & \\
\hline II & 39 & 19 & \\
\hline II & 14 & 13 & \\
\hline \multicolumn{4}{|l|}{ Comorbidity } \\
\hline High blood pressure & 31 & 19 & 0.82 \\
\hline Diabetes & 13 & 14 & 0.15 \\
\hline Lung disease & 6 & 2 & 0.46 \\
\hline Heart and brain disease & 9 & 10 & 0.12 \\
\hline Tumor stage & & & 0.40 \\
\hline $\mathrm{I}+\mathrm{II}$ & 49 & 28 & \\
\hline III & 24 & 19 & \\
\hline Surgical method & & & 0.26 \\
\hline Total gastrectomy & 34 & 17 & \\
\hline Distal stomach & 39 & 30 & \\
\hline Reconstruction method & & & 0.12 \\
\hline Bi I & 5 & 1 & \\
\hline Bi II & 32 & 29 & \\
\hline Roux-en-Y & 36 & 17 & \\
\hline Operation time & $236.2 \pm 60.8$ & $242.5 \pm 59.6$ & 0.49 \\
\hline Amount of bleeding (ml) & $182 \pm 73$ & $176 \pm 68$ & 0.65 \\
\hline Number of lymph node dissections & $29.5 \pm 11.4$ & $29.6 \pm 10.5$ & 0.96 \\
\hline
\end{tabular}

Note: BMI is the height and body mass index; ASA is graded by the American Society of Anesthesiologists.

The perioperative management measures were also collected (Table 2).

Table 2: Perioperative management measures for accelerated rehabilitation and control groups 


\begin{tabular}{|c|c|c|}
\hline $\begin{array}{l}\text { Perioperative } \\
\text { measures }\end{array}$ & Accelerated rehabilitation group & Control group \\
\hline $\begin{array}{l}\text { Preoperative } \\
\text { education }\end{array}$ & $\begin{array}{l}\text { ERAS-related health education was performed before } \\
\text { surgery; lung function forging and atomization preparation } \\
\text { were performed, and smokers were quitting before } \\
\text { surgery. }\end{array}$ & no \\
\hline $\begin{array}{l}\text { Gastrointestinal } \\
\text { preparation }\end{array}$ & $\begin{array}{l}\text { Lactulose was taken orally } 1 \text { day before surgery, and } \\
\text { banned } 6 \text { hours before surgery water }\end{array}$ & $\begin{array}{l}\text { Hours before the operation, } \\
\text { and } 6 \text { hours without water }\end{array}$ \\
\hline $\begin{array}{l}\text { Intragastric } \\
\text { tube placement }\end{array}$ & $\begin{array}{l}\text { Gastric tubes are not routinely placed, and patients with } \\
\text { gastric tubes are usually removed on the first day after } \\
\text { surgery. }\end{array}$ & $\begin{array}{l}\text { Place the gastric tube } \\
\text { regularly and remove it after } \\
\text { venting the anus }\end{array}$ \\
\hline Catheter & Removal on day 1 after surgery & $\begin{array}{l}\text { Removal within } 2-3 \text { days after } \\
\text { surgery }\end{array}$ \\
\hline $\begin{array}{l}\text { Postoperative } \\
\text { analgesia }\end{array}$ & $\begin{array}{l}\text { Local anesthesia with ropivacaine for surgical incision }+ \\
\text { intravenous controlled analgesia pump }+ \text { parecoxib }\end{array}$ & $\begin{array}{l}\text { Intravenous self-controlled } \\
\text { analgesia pump }\end{array}$ \\
\hline $\begin{array}{l}\text { Get out of bed } \\
\text { after surgery }\end{array}$ & $\begin{array}{l}\text { Assist patients to turn up and sit up on the day of surgery, } \\
\text { encourage patients to get out of bed on the first day after } \\
\text { surgery, and assist patients to walk on the second day }\end{array}$ & $\begin{array}{l}\text { Encourage patients to get out } \\
\text { of bed as early as possible, } \\
\text { depending on the patient's } \\
\text { wishes }\end{array}$ \\
\hline Eating & $\begin{array}{l}\text { Drink a small amount of water on the first day after } \\
\text { surgery, and a liquid diet on the second and third days, } \\
\text { and gradually transition to a semi-liquid diet. }\end{array}$ & $\begin{array}{l}\text { Anal venting, water intake } \\
\text { after gastrointestinal tube } \\
\text { removal }\end{array}$ \\
\hline
\end{tabular}

\section{The comparison of clinical data after surgery}

Laparoscopic surgery was successfully performed in both groups. Compared with the control group, the time to first get out of bed, the first time to eat liquid food after surgery, the postoperative anal recovery time, and the postoperative hospital stay were lower in the accelerated rehabilitation group $(P<0.05)$. There was no significant difference in the overall complication rate between the two groups $(P>0.05)$, but the postoperative pulmonary infection rate in the accelerated rehabilitation group was significantly lower than that in the control group $(1.4 \%$ vs $10.6 \%, \mathrm{P}<0.05)$. One patient died in the perioperative period, and the difference was not statistically significant $(P>0.05)$. See Table 3 for details.

Table 3: Comparison of related indicators after surgery between the two groups 


\begin{tabular}{lccc}
\hline Group & $\begin{array}{c}\text { Accelerated rehabilitation group } \\
(\mathrm{n}=73)\end{array}$ & $\begin{array}{c}\text { Control group } \\
(\mathrm{n}=47)\end{array}$ & P value \\
\hline Bedtime (day) & $2.1 \pm 0.9$ & $3.8 \pm 1.5$ & $<0.01$ \\
Anal exhaust time (day) & $3.2 \pm 0.8$ & $3.9 \pm 1.2$ & $<0.01$ \\
Fluid time (day! & $1.8 \pm 0.9$ & $3.2 \pm 1.3$ & $<0.01$ \\
Total postoperative complications (\%) & $11(15.1)$ & $10(21.3)$ & 0.38 \\
Pulmonary infections (\%) & $1(1.4)$ & $5(10.6)$ & 0.03 \\
Anastomotic leakage (\%) & $4(5.5)$ & $1(2.1)$ & 0.66 \\
Duodenal stump leakage (\%) & $2(2.7)$ & $1(2.1)$ & 0.69 \\
Celiac infection (\%) & $4(5.5)$ & $2(4.3)$ & 0.89 \\
Gastroparesis (\%) & $1(1.4)$ & $1(2.1)$ & 0.68 \\
Other (\%) & $3(4.1)$ & $2(4.3)$ & 0.67 \\
Length of hospital stay (day) & $12.7 \pm 4.3$ & $15.8 \pm 6.4$ & $<0.01$ \\
Death case (\%) & $1(1.4)$ & $1(2.1)$ & 0.68 \\
\hline
\end{tabular}

Note: In other complications, 1 case of pleural effusion, 1 case of urinary tract infection and 1 case of atrial fibrillation were performed in the accelerated rehabilitation group. The control group was complicated with pleural effusion in 2 cases.

\section{Discussion}

Gastric cancer is one of the most common malignant tumors in China, and Surgery is the only radical approach. As aging has become a social problem, the number of elderly patients with gastric cancer is also increasing. However, due to cardiopulmonary complications increasing, physical function declining, relatively low immunity, and malnutrition of elderly patients, postoperative complications will be increased and recovery will be slow after abdominal surgery $[6,7]$. Therefore, it is a hot topic in clinical research on how to promote the rapid recovery of laparoscopic radical gastrectomy cancer for elderly patients.

ERAS was first proposed by Kehlet, a Danish scholar. It adopts a series of evidence-based medical management measures to reduce the patient's surgical stress and postoperative complications effectively, and promote patient's rehabilitation. The optimization management measures include preoperative education, intraoperative warming, early post-extubation, early getting out of bed, early eating after surgery and so on [8]. EARS is widely promoted and proves to have following characteristics $\mathbb{Z}$ shorten postoperative hospital stay after surgery, reduce postoperative complications, ease pain and improve postoperative recovery $[8,9]$. In this study, the time for the first time to get out of bed in the accelerated rehabilitation group, postoperative liquid food intake time, and the anal recovery exhaust time were significantly lower than those in the control group; the postoperative hospital stay was also significantly lower than that in the control group, which is consistent with the results reported in the literature $[4,10]$.

For elderly patients, most surgeons prefer to adopt conservative treatments during perioperative management. In order to prevent aspiration during anesthesia and surgery, patients require long time 
fasting before surgery. However, some studies [11]show that long period fasting will cause hunger, anxiety and energy consumption of the body, which easily disorders patient's internal environment, reduces their stress ability, and decreases resistance and immunity. Traditionally, bowel preparation is required before abdominal surgery. But there are reports showing that bowel preparation may increase risk of surgical complications, such as abdominal adhesions, flora imbalance, fluid and electrolyte disorders, infection risk increasing, anastomotic leak and so on [12]. Compared with ERAS group and control group, there were no statistically significant differences in postoperative complication rate $(15.1 \%$ vs $21.3 \%, P=0.38)$, anastomotic leak rate, infection risk and Duodenal stump leakage ( $5.5 \%$ vs $2.1 \%$ $, P=0.66 ; 5.5 \%$ vs $4.3 \%, P=0.89 ; 2.1 \%$ vs $2.7 \%, P=0.69)$, which is similar to Tweed's [5] research. The main reason should be ERAS group does not perform bowel preparation before surgery, which ensures the normal intestinal flora and reduces the postoperative inflammatory response. The ERAS group also has early postoperative intake, which reduces digestive juice loss, avoids fluid and electrolyte disorders, and enhances the intestinal function recovery. In traditional concept, gastrointestinal tract will be paralyzed after surgery, so indwelling gastric tube should be placed to observe and reduce postoperative complications. But most of elderly patients have cardiopulmonary complications, in that case indwelling gastric tube may cause sputum blockage and lung infection. Besides, indwelling gastric tube restricts patient's activity, and then increases the risk of deep venous thrombosis. In this study, the incidence of lung infection of ERAS group is obviously lower than Control group ( $1.4 \%$ vs $10.6 \%, \mathrm{P}=0.03)$. Nonindwelling gastric tube for ERAS group is one of the reasons, and the other one is the group will organize a series of activities for elderly patients, like ERAS conception propaganda before surgery, respiratory function exercise, routine atomization inhalation, back patting after operation, encouraging patients to get out of bed earlier, cough and expectoration.

\section{Conclusions}

In summary, the application of ERAS concepts and measures during the perioperative period of laparoscopic radical gastrectomy cancer for patients aged $\geq 70$ years can not only promote rapid postoperative recovery, reduce postoperative hospital stay, but also reduce postoperative incidence of lung infection. The concept and measures are worthy of application and promotion in elderly patients undergoing laparoscopic radical gastrectomy cancer. Of course, this study is a retrospective study. It is inevitable that there is selection bias. The analgesic effect of postoperative patients and the improvement of anesthesia during the operation have not been studied. These will be the directions for further research.

\section{Abbreviations}

ASA: American Society of Anesthesiologists, BM: body mass index, ERAS: enhanced recovery after surgery

\section{Declarations}




\section{Ethics approval and consent to participate}

This study was approved by the Human Research Ethics Committee of Zhejiang Provincial People's Hospital and performed in accordance with World Medical Association Declaration of Helsinki. All patients included in the study consented to participated in the research by signing nationally approved consent forms.

\section{Consent for publication}

All subjects have written informed consent.

\section{Availability of data and materials}

The authors declare that all relevant data supporting the finding of this study are available within the paper. All data are available from the corresponding author on reasonable request.

\section{Competing interests}

The author had no conflict of interest in relation to this study.

\section{Funding}

This work was supported by Natural Science Foundation of Zhejiang Province (LY20H160045, LQ2OH200004, LY20H080009) and Zhejiang Medical and Health Science and Technology Program (2020RC021, 2020KY015, 2018KY243). The funder had no role in the process of study design, data analysis, decision to publish or preparation of manuscript.

\section{Author Contributions}

Jun Ma designed the study and wrote the manuscript; Hongliang Shao collected the data; Yanzhong Wang analyzed the data; Yirui Chen reviewed and edited the manuscript; Yiping Mou conceived and designed the study. All authors read and approved the manuscript.

\section{Acknowledgement}

None

\section{Authors' Information}

Jun Ma

Address: 158 Shangtang Road, Hangzhou, Zhejiang, P.R. China, 310014

Tel囚+86-571-85893407

E-mail: mjys2012@aliyun.com 
Hongliang Shao

Address: 156 North Yingzhou Road, Fuyang, Anhui, P.R. China, 236001

Tel囚+86-558-2196656

E-mail: 1210201015@qq.com

Yanzhong Wang

Address: 3 East Qingchun Road, Hangzhou, Zhejiang 310016, P.R. China

Telephone Number: +86-571-88206875

Email address: lanzhijunsx@hotmail.com

Yirui Chen

Address: 158 Shangtang Road, Hangzhou, Zhejiang, P.R. China, 310014

Tel囚+86-571-85893407

E-mail: daisy_chen1986@163.com

Yiping Mou

Address: 158 Shangtang Road, Hangzhou, Zhejiang, P.R. China, 310014

Tel囚+86-571-85893408

E-mail: yp66self@163.com

Corresponding Author:

Yiping Mou

Department of Gastrointestinal and Pancreatic Surgery

Zhejiang Provincial People's Hospital, People's Hospital of Hangzhou Medical College

Address: 158 Shangtang Road, Hangzhou, Zhejiang, P.R. China, 310014

Tel囚+86-571-85893408

Fax: $+86-571-87091089$

E-mail: yp66self@163.com 


\section{References}

1. Ripolles-Melchor J, Ramirez-Rodriguez JM, Casans-Frances R, Aldecoa C, Abad-Motos A, LogronoEgea M, et al. Association Between Use of Enhanced Recovery After Surgery Protocol and Postoperative Complications in Colorectal Surgery: The Postoperative Outcomes Within Enhanced Recovery After Surgery Protocol (POWER) Study. JAMA Surg. 2019;1548:725-736.

2. Schram A, Ferreira V, Minnella EM, Awasthi R, Carli F, Scheede-Bergdahl C. In-hospital resistance training to encourage early mobilization for enhanced recovery programs after colorectal cancer surgery: A feasibility study. Eur J Surg Oncol. 2019;459:1592-1597.

3. Aoyama T, Yoshikawa T, Sato T, Hayashi T, Yamada T, Ogata T, et al. Equivalent feasibility and safety of perioperative care by ERAS in open and laparoscopy-assisted distal gastrectomy for gastric cancer: a single-institution ancillary study using the patient cohort enrolled in the JCOG0912 phase III trial. Gastric Cancer. 2019;223:617-623.

4. Kang SH, Lee Y, Min SH, Park YS, Ahn SH, Park DJ, et al. Multimodal Enhanced Recovery After Surgery (ERAS) Program is the Optimal Perioperative Care in Patients Undergoing Totally Laparoscopic Distal Gastrectomy for Gastric Cancer: A Prospective, Randomized, Clinical Trial. Ann Surg Oncol. 2018;2511:3231-3238.

5. Tweed T, van Eijden Y, Tegels J, Brenkman H, Ruurda J, van Hillegersberg R, et al. Safety and efficacy of early oral feeding for enhanced recovery following gastrectomy for gastric cancer: A systematic review. Surg Oncol. 2019;28:88-95.

6. Renz BW, Khalil PN, Mikhailov M, Graf S, Schiergens TS, Niess H, et al. Pancreaticoduodenectomy for adenocarcinoma of the pancreatic head is justified in elderly patients: A Retrospective Cohort Study. Int J Surg. 2016;28:118-125.

7. Riediger $\mathrm{H}$, Krueger $\mathrm{CM}$, Makowiec F, Adam U. [Impact of Age and Comorbidity on Perioperative Mortality after 250 Pancreatic Head Resections]. Zentralbl Chir. 2016;1413:270-276.

8. Ni X, Jia D, Chen Y, Wang L, Suo J. Is the Enhanced Recovery After Surgery (ERAS) Program Effective and Safe in Laparoscopic Colorectal Cancer Surgery? A Meta-Analysis of Randomized Controlled Trials. J Gastrointest Surg. 2019;237:1502-1512.

9. Kowalsky SJ, Zenati MS, Steve J, Esper SA, Lee KK, Hogg ME, et al. A Combination of Robotic Approach and ERAS Pathway Optimizes Outcomes and Cost for Pancreatoduodenectomy. Ann Surg. 2019;2696:1138-1145.

10. Zang YF, Li FZ, Ji ZP, Ding YL. Application value of enhanced recovery after surgery for total laparoscopic uncut Roux-en-Y gastrojejunostomy after distal gastrectomy. World J Gastroenterol. 2018;244:504-510.

11. Lamacraft G, Labuschagne C, Pretorius S, Prinsloo MC, Smit MD, Steyn JR. Preoperative fasting times: Prescribed and actual fasting times at Universitas Hospital Annex, Bloemfontein, South Africa. S Afr Med J. 2017;10710:910-914. 
12. Slim K, Vicaut E, Launay-Savary MV, Contant C, Chipponi J. Updated systematic review and metaanalysis of randomized clinical trials on the role of mechanical bowel preparation before colorectal surgery. Ann Surg. 2009;2492:203-209. 